\title{
The effect of learning by the seven-cycle learning(7E's) strategy on the achievement in English language for sixth grade female students in Karak Governorate
}

\author{
ZAHERA ABDUL-AZIZ SA'IDS.BANI ATTIH \\ Zaherabanyatyeih7@gmail.com \\ THE HASHEMITE KINGDOM OF JORDAN \\ (THE MINISTERY OF EDUCATION) \\ DOI: 10.29322/IJSRP.11.08.2021.p11604 \\ http://dx.doi.org/10.29322/IJSRP.11.08.2021.p11604
}

\begin{abstract}
The study aimed to investigate the effect of learning using the seven-cycle learning(7E's)strategy on the achievement in English language for sixth grade female students in Karak Governorate. The quasi-experimental approach was used to conduct the study. The study sample consisted of (85) female students who were randomly selected from Mahmoudiyah Basic Mixed School. The study sample was divided into two groups: an experimental group consisting of (42) students, who studied using the sevencycle learning strategy, and the control group consisting of (43) female students, who studied using the traditional method. To achieve the study objectives, the researcher prepared a guide for the teacher and student according to the steps of the seven-cycle learning strategy in teaching English grammar, and an achievement test consisting of (20) multiple choice- items was developed. The validity and reliability of the tool were verified, and the study results indicated that there were statistically significant differences $(\alpha \leq 05.0)$ between the means of the female students' scores in the post-achievement test in favor of the experimental group. The study recommended training the supervisors and teachers of humanities on the seven-course learning course, and in particular the teachers of the English language.
\end{abstract}

Keywords: learning cycle strategy, achievement, sixth grade.

\section{INTRODUCTION}

Modern education is concerned with teaching thinking and refining its skills, so that the learner can use the knowledge and information he obtains to achieve the success he aspires to. That is because thinking is an indispensable necessity in the lives of peoples and societies; The nation'svalue is no longer measured only by its natural wealth, but also by its possession of minds used to form and develop knowledge, and its assimilation of the amazing technological and informational changes that are taking place. Thisnecessitates preparation individuals who can adapt to scientific developments, and this will only come through elaborating teaching strategies to develop students' thinking skills.

Hence, developing thinking has become one of the instructive subjects that get care and consideration in current educational methods. The objective of the educational procedure is no extended confined to providing students with knowledge and facts and filling their minds with them, but rather to develop their abilities to think properly. Education is based on the principle of teaching the student how to learn and how to think (Al-Sabbagh, 2013; Najm, 2012).

The cycle learning is one of the teaching models that make the learner participate positively in the learning process, because it is a reflection of some ideas of Jean Piaget's cognitive constructivist theory (Zaytout, Zeytoun, 2006), in which the learner constructed knowledge as learning is not imposed but rather taken by the learner.Therefore, the learning cycle takes into account students' mental 
abilities, presents science as a method, research and thinking, and pushes the student to think, and thus is concerned with the development of thinking skills.

Among the strategies that are concerned with developing the learner's thinking and practical skills and consistent with the way students learn is the strategy of the seven-cycle learning. Through this cycle, the students themselves undertake the process of investigation, exploration, and research in the constructivist theory (Al-Majali, 2016).

\subsection{STUDY PROBLEM, QUESTIONS AND HYPOTHESES}

English language curricula have received constant attention; Because it is one of the main cornerstones in developing female students' experience, through which they are taught and trained toorganize and sequence ideas, so that they can apply what they have learned in different and new situations.Despite the changes that have occurred in the content of the English language curricula, they have not been accompanied by a significant change in teaching strategies. Strategies that depend on narration and recitation are still the prevailing and followed (Al-Majali, 2016).

This study attempts to answer the following main question:

What is the effect of learning by the seven-cycle learning strategy on the achievement of English language for sixth grade female students in Karak Governorate?

The following null hypothesis emerges from this question:

- There are no statistically significant differences at $(\alpha \leq 05.0)$ between the mean scores of the two study groups in the post-achievement test ascribed to the teaching method (the seven-cycle learning strategy, and the traditional method). 


\subsection{STUDY IMPORTANCE}

This strategy is in line with the call to activate the role of female students through investigation, and is distinguished from others in that it takes into account learners' mental abilities. The teacher provides the learner with concepts he can learn, and the learning proceeds from the part to the whole, and it causes the learner to think using the concept of disequilibrium, which It is the main motive towards searching for more scientific knowledge, and stimulating the thinking skills of the learners.

The importance of the current research can be summarized in the following:

1. Providing models for lessons that include teaching topics in English grammar forthe sixth grade, according to the strategy of the seven- cycle learning.

2. The current study presents a test to measure the level of achievement in teaching English grammar for the sixth grade, and this may help in constructing other tests for variety of topics in the English language.

3. It may help experts, specialists, supervisors, teachers and those interested in present a teaching strategy that may contribute to develop the achievement of sixth grade students.

\subsection{GLOSSARY OF STUDY}

\section{- THE (7 E”S) LEARNING CYCLE WAS DEFINED AS:}

- Zeitoun (2007): an educational-learning model that consists of seven procedural steps that an English language teacher uses with students in the classroom or in the educational field in order for students to build their own knowledge on the one hand and develop concepts and skills on the other hand.

- The researcher adopted Zeitoun's definition(2007) as a theoretical definition of the seven-cycle learning. the researcher defines seven - cycle learning procedurally as: a sequence of organized steps derived from the constructivism applied by the researcher on the members of the experimental group through preparing them to study English language and directing them to discover the knowledge and assignment to explain the subject and the interpretation of its contents. This resulted in the expansion of the application of concepts in English into new life situations, then ideas and experiences are exchanged and misconceptions are changed. Finally, the students will be tested in order to assess their understanding of the concepts and skills they have learned.

- Achievement: in this study, achievement is procedurally defined as the student's score in the achievement test in English grammar teaching prepared by the researcher for this purpose.

- Sixth grade students: They are students aged (10-11 years) who study in the sixth grade for the academic year 2019/2020.

\subsection{STUDY LIMITATIONS}

- The sample of this study was limited to (85) students from the sixth grade from Mahmudiya Mixed School in Karak Governorate.

- This study was conducted in teaching English grammar from the first semester English language textbook for the sixth grade.

- The study was conducted in the first semester of the 2019/2020 academic year.

\subsection{THEORETICAL FRAMEWORK AND PREVIOUS STUDIES}

The constructivist theory is one of the intellectual approaches that emerged in the modern era and formed a revolution in research and application in the humanities and social studies as well as in ways of tackling knowledge acquisition where educationhas 
received the greatest share of that impact. it has become a holistic approach and educational activity and an important introduction to education. It has been the focus educationalists during the recent two decades. Despite its interference with the cognitive school in many aspects, it is distinguished by its emphasis on learning through the use of real contexts. As well as its emphasis on the social dimension to achieve learning. Many modern teaching strategies have been based on the constructivist theory, such as the learning cycle, the constructivist learning model, the Targetsmodel, and others. This made it possible for the learner to construct knowledge within a real realistic and social environment that allows him to gain concepts through his own activity and practice and enable him to review his knowledge structure.

\section{FOUNDATIONS OF THE CONSTRUCTIVIST THEORY:}

1. It is based on learning, rather than teaching.

2. It encourages learners to research and investigate.

3. Encourage learners to participate in competition and social interaction.

4. It makes learners creative.

5. It puts learners in real situations and problems.

6. It encourages students' independence and its acceptance.

7. Emphasizes performance and understanding when evaluating the learner.

8. Ittakes the mental model into account. (Qarni, 2013: 236).

\section{THE TEACHER'S ROLE IN THE CYCLE LEARNING STRATEGY:}

As for the role of the teacher who uses the cycle learning strategy in instruction, they are as follows:

1. Determining the concepts that he wants to present to the learners and enable them to do so.

2. Formulating the problems included in the learning activities at each stage, provided that these problems are compatible with the learners' abilities.

3. Creating sensory experiences and activities related to the concept.

4. Planning the lesson, and determining how the concept is presented in light of the activities that are practiced in the discovery phase.

5. Developing a detailed plan that includes application procedures, and everything that would enable learners to use the concept in broader applications.

\section{FEATURES OF THE LEARNING CYCLE STRATEGY:}

There are several advantages of a learning cycle strategy, including:

1. It allows the individual learner to interact positively with the educationalprocess.

2. It is important to relate what is theoretical with what is practical, and this leads the learner to the correct learning, which remains in the mind.

3. It provides the opportunity for teaching with advanced tools, techniques, and therefore knowledge must be formed positively.

4. It meets learners' needs, enhances the level of their interests, and ultimately leads to an increase in their cognitive level.

5. It provides learners with an opportunity to practice science and discover some knowledge as a result of the activities they undertake. 
6. It is suitable for all levels of learners.

7. It causes the learner to think, through the use of the concept of disequilibrium, which is the main motive towards searching for more scientific knowledge.

8. It is concerned with developing learners' thinking skills.

\section{SEVEN-CYCLE LEARNING STRATEGY:}

The constructivist seven-cycle learning strategy is one of the elaborated cycle learning strategies, as it started with three stages: (Exploration, explanation of the concept, and its application, then it was developed into four stages: Exploration, explanation, application, and evaluation). After that, it was developed into five stages:

(engagement, exploration, explanation, expansion, and evaluation, and then it developed into seven phases, which represent the seven-stage strategy of constructivism in its following stages: excitement,engagement, exploration, explanation, expansion, exchange, examination, (Zeitoun 2007:455.)

In this context, the procedural steps of the seven stages of the constructivist learning strategy were adopted in this study, and the researcher clarifies that the development of the cycle learning strategies with its sequential and organized stages emerged from the constructivist theory.

The Miami Museum experts presented the seven stages (and each stage begins with the letter E) and their procedural steps as follows, according to what was mentioned (Zeitoun2007: 457-459):

First: The Excitement stage: This stage or step aims to motivate the students and arouse their curiosity and interest in the subject of learning or the concept when they ask some questions as in: Why did this happen? What can I discover regarding this subject? In order for the students to reach this stage, it is necessary to do one or more activities related to learning the subject or concept. The role of the English language teacher at this stage is to generate enthusiasm, produce interest, increase questions, inspire prediction, and stimulate the student.

Second: The Exploration stage: This stage purposes to satisfy the students' interest by supplying them with experiences and cooperation together to comprehend and realized the meaning of the concept. The students' role is represented in exploration and research to satisfy their curiosity with regard to the concept. They also think freely within the limits of their activity, formulate new explanatory hypotheses and predictions, give-and-take debates with their classmates in supportive learning groups, record observations and ideas and comment on events and observations.

Third: Explanation stage: This stage purposes to clarify and clarify the idea to be learned and define terms. The student's role is to refer to various bases of facts, including chat meetings and communication with the teacher to approach definitions and explanations of the concept to be researched and studied, as well as explaining possible answers and solutions, benefiting from the interpretations of others and presenting them to colleagues to be criticized, and listening and understanding the explanations the teacher provides.

Fourth: Expansion stage: It aims at discovering new applications of the concept,where the student discovers new applications of the concept. He uses the terms of other concepts, asks questions, employs these expressions, and draws acceptable conclusions. $\mathrm{He}$ is asked to ensures thathis colleagues understand what is presented to them, presents reasonable realistic conclusions with evidence, and formulates decisions

Fifth: Extension stage: It aims to clarify the relationship between the concept and other concepts. In this stage, the conceptisextended to new topics in other subjects and branches of study.

Sixth: The Exchanging Stage: It aims at exchanging or changing ideas or experiences. In which the student publishes the outcome of his efforts, the results of his research and his interpretations individually or withintheteam work that he worked with, This publication is licensed under Creative Commons Attribution CC BY. 
and this of course requires giving the students the opportunity to present their results to each other reciprocally among the teams or collectively in front of the class. As for the role of the teacher, it is to relate information about the concept or topic with other concepts and topics.

Seventh: The Examination stage: It aims to assess the students' learning of the concepts, skills and processes that have been learned, and the student's role is to respond to the open-ended questions using acceptable previous notes, evidence and explanations. Demonstrating conceptual understanding and skills. Present his progress in scientific knowledge, and use the alternative evaluation of evidence for his understanding of the concept or topic.

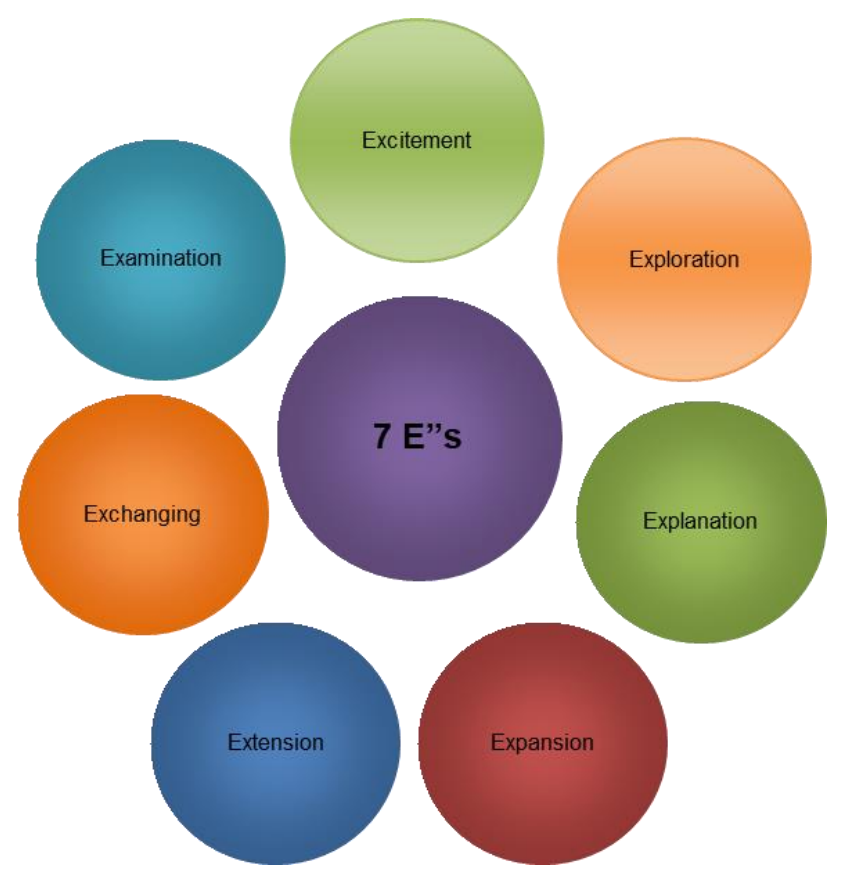

THE SEVEN STAGES OF THE LEARNING CYCLE (7E'S).

The teacher's role is to observe students during the application of concepts, skills and new processes, and evaluate students' knowledge and skills as well as search for evidence that students have. Another role is to identify their ability to change their thoughts or behavior, and allow them to assess their knowledge and practical and collaborative skills and alike. (Zeitoun 2007: 457-459).

\subsection{PREVIOUS STUDIES:}

Al-Tarawneh study (2011) meant to investigate the consequence of using the modified cycle book learning in emerging critical rational abilities for tenth grade female students. The study sample consisted of (98) female students distributed between two sections of the tenth grade at Bab Al-Wad Secondary School for Girls in Amman. The researcher used the California test for critical thinking skills, which consisted of (54) multiple-choice items. The results of the study showed that there were statistically significant differences between the arithmetic means of the female students' scores in the two study groups on the critical thinking skills test attributed to the teaching strategy, and supporting the students who studied using the modified cycle learning.

(Al-Shehri, 2016) conducted a study intended to know the outcome of using the seven-cycle learning approach in teaching a unit of the English language book for the fifth grade in evolving accomplishment and retention of learning, and the researcher monitored the quasi-experimental method. The study sample comprised of (59) students, who were divided into Two groups: an experimental group, (30) students, and a control group (29) students from a school in Najran, Saudi Arabia. The researcher prepared an achievement test consisting of (22) items, and one of the results of the research was the superiority of the students of the experimental group who studied using the five-cycle strategy overthe control group in the achievement in the post-test, as well as in the retention of learning. 
(Al-Azmiya and Sherhid, 2015) conducted a study expected at knowing the consequence of using the five-cycle learning policy in teaching a unit of mathematics for the seventh grade in emerging attainment and mathematical thinking among students in Abyan Governorate - Republic ofYemen. The two researchers implemented the experimental approach with pre and post test.

The study comprised of (80) students who were divided equally into two groups: ("experimental and control"), and the researcher organized two tests: the first for achievement andconsisted of (24) items, and the second for mathematical thinking with (24) items. the results of the research showed superiorityof the students in the experimental group who was taught using the five-cycle learning strategy over the control group in achievement and in mathematical thinking skills (generalization, induction, symbolic expression, logical thinking, and mathematical proof), as well as in the mathematical thinking test as a whole, but there were no statistically significant differences between the two groups: experimental and control in deduction skill.

\subsection{METHODOLOGY:}

The researcher implemented the quasi-experimental method as it suits the nature of the current study, using two groups: the experimental group, which was taught by the seven-cycle learning method, and the control group, which was taught through the traditionalmethod, according to the following table (1):

Table (1): Experimental design of the study:

\begin{tabular}{|c|c|c|}
\hline Group & Independent variable & Dependent variable \\
\hline Experimental group & Five-cycle learning strategy & - achievement \\
\hline Control group & Traditional method & \\
\hline
\end{tabular}

\subsection{STUDY POPULATION}

The study population comprised of the sixth grade students in the "Directorate of Education of Karak Governorate" during the first semester of the academic year 2019/2020, and their number is (1168) female students for the year 2020, distributed among (47) public schools.

As for the study members, their number was (65) female students of the sixth grade from the elementary mixed school of Mahmoudiya in the Kasbah of Karak governorate. They were chosen intentionally due to the cooperation of its administration and teachers with the researcher in the application of the study. The students were circulated in a simple haphazard way into two groups:

- $\quad$ Experimental group:they were taughtEnglish grammar sing the seven-cycle learning strategy, and its number was (32) femalestudents.

- Control group: It studied English grammar using the traditional method, and its number was (33) female students.

\subsection{THE EQUIVALENCE OF THE TWO STUDY GROUPS}

To verify the equivalence of the experimental and control groups in achievement before application, the arithmetic means and standard deviations of the members of the two study groups were calculated on the pre-achievement test, then the results of the ttest for independent samples were calculated to indicate the differences between the groups' means, and Table (2) shows these results.

Table (2): Arithmetic averages, standard deviations, and ( $t$ )-test results for the differences between the scores of female students of the two groups: the control and experimental on the pre-achievement test. 
International Journal of Scientific and Research Publications, Volume 11, Issue 8, August 2021

\begin{tabular}{|c|c|c|c|c|c|}
\hline Group & Number & Arithmetic mean & Standard deviation & (t) value & Statistical significance \\
\hline Experimental & 42 & 9.25 & 1.81 & \multirow{2}{*}{0.13} & 0.841 \\
\cline { 1 - 4 } Control & 43 & 9.19 & 2,38 & & \\
\hline
\end{tabular}

Statistical significance in the pre-achievement test indicated that there were no statistically significant differences $(\alpha \leq 0.05)$ between the mean scores of the pre-achievement test for the experimental and control groups, and this indicated the equivalence of the groups in the sample.

\subsection{STUDY TOOLS}

- $\quad$ Preparing the teacher's and student's guide by the researcher for the unit to which the study is to be applied.

- $\quad$ Relying on the theoretical basis of the seven-cycle learning strategy.

- Developing an achievement test by researchers that consists of (20)multiple-choice items.

- Difficulty and discrimination coefficients for theitems of achievement test. 
Table (3): Difficulty and discrimination coefficients were calculated for the items

of the achievement test

\begin{tabular}{|c|c|c|c|c|c|}
\hline $\begin{array}{c}\text { Item } \\
\text { number }\end{array}$ & $\begin{array}{c}\text { Difficulty } \\
\text { coefficient }\end{array}$ & $\begin{array}{c}\text { Discrimination } \\
\text { coefficient }\end{array}$ & $\begin{array}{c}\text { Item } \\
\text { number }\end{array}$ & $\begin{array}{c}\text { Difficulty } \\
\text { coefficient }\end{array}$ & $\begin{array}{c}\text { Discrimination } \\
\text { coefficient }\end{array}$ \\
\hline 1 & 0.55 & 0.45 & 11 & 0.44 & 0.56 \\
\hline 2 & 0.60 & 0.40 & 13 & 0.50 & 0.50 \\
\hline 3 & 0.72 & 0.28 & 14 & 0.68 & 0.32 \\
\hline 4 & 0.40 & 0.60 & 15 & 0.68 & 0.32 \\
\hline 5 & 0.39 & 0.61 & 16 & 0.80 & 0.20 \\
\hline 6 & 0.64 & 0.36 & 17 & 0.55 & 0.45 \\
\hline 7 & 0.66 & 0.34 & 18 & 0.30 & 0.70 \\
\hline 8 & 0.42 & 0.58 & 0.44 & 20 & 0.47 \\
\hline 10 & 0.46 & 0.54 & 0.65 & 0.35 \\
\hline
\end{tabular}

** Statistically significant at the level of significance $(\alpha \leq 0.05)$

"As for the reliability of the achievement test, it was applied to a sample of female students from outside the study sample who studied the chosen unit, and the sample consisted of (28) female students from the sixth grade, and it was re-applied after two weeks on the members of the same sample.The Pearson correlation coefficient was calculated for the members of the pilot sample in Both times and was (0.92). The internal consistency coefficient was also calculated, and the Cronbach's coefficient alpha was (0.82)".

\section{.35STUDY PROCEDURES}

- $\quad$ Preparing the study tool of the achievement test.

- $\quad$ Arbitration of the study tool of achievement test by a group of arbitrators

- $\quad$ Applying the achievement test to the pilot sample.

- $\quad$ Ensuring that the study groups are equivalent before applying the achievement test.

- $\quad$ Applying the achievement test to the students of the two groups, the experimental group and the control group, with the aim of applying the lessons according to the strategy of the seven-cycle learning.

- $\quad$ Extracting and interpreting the results of the study. 


\section{.36 STUDY VARIABLES}

1. The independent variable: the teaching method and it has two levels (the seven-cycle learning, the traditional method).

2. The dependent variable: (achievement).

\section{.37 STUDY RESULTS AND DISCUSSION}

"Results related to the hypothesis and its discussion":

"There was no statistically significant difference at the level $(\alpha \leq 05.0)$ between the mean scores of the members of the two study groups in the post-achievement test attributed to the teaching method (seven cycle learning, and the traditional method)".

"To verify this hypothesis, the arithmetic means and standard deviations of female students' scores in the experimental and the control group were calculated on the pre and post achievement test, as shown in Table (4)".

Table (4): Arithmetic averages and standard deviations of the scores of the students of the two groups: the control and experimental on the pre and post achievement test.

\begin{tabular}{|c|c|c|c|c|c|}
\hline \multirow{2}{*}{ Group } & \multirow{2}{*}{ Number } & \multicolumn{2}{|c|}{ Pre test } & \multicolumn{2}{|c|}{ Post test } \\
\cline { 3 - 6 } & & Arithmetic means & $\begin{array}{c}\text { Standard } \\
\text { deviation }\end{array}$ & $\begin{array}{c}\text { Arithmetic means } \\
\text { deviation }\end{array}$ & 15.58 \\
\hline Experimental & 42 & 9.25 & 1.81 & 12.77 & 4.42 \\
\hline Control & 43 & 9.19 & 2.38 & 5.16 \\
\hline
\end{tabular}

"It is noted from Table No. (4) that there were apparent differences between the meanscores of the two groups: experimental, and control, and to find out whether these differences were statistically significant at the level of significance $(\alpha \leq 05.0)$, an analysis of covariance (ANCOVA) was performed, and Table (5) shows this analysis”.

Table (5): The results of the analysis of covariance (ANCOVA) for the difference between the means of the female students'post-achievement test of the two study groups

\begin{tabular}{|c|c|c|c|c|c|}
\hline $\begin{array}{c}\text { Source of } \\
\text { variation }\end{array}$ & $\begin{array}{c}\text { Sum of } \\
\text { squares }\end{array}$ & df & $\begin{array}{c}\text { Mean of } \\
\text { squares }\end{array}$ & F value & $\begin{array}{c}\text { Statistical } \\
\text { significance }\end{array}$ \\
\hline Pre test & 711.91 & 1 & 711.91 & 68.59 & 0.21 \\
\hline Group & 100.80 & 1 & 100.80 & 9.71 & 0.00 \\
\hline Error & 266.90 & 82 & 5.93 & & \\
\hline Total & 1079.61 & 84 & & & \\
\hline
\end{tabular}

*Statistically significant $(\alpha \leq \mathbf{0 5 . 0})$.

It is clear from Table (5) that "there were statistically significant differences between the mean scores of the female students in the post-achievement test in favor of the experimental group. Where the statistical significance was $(0.00)$ )"

Thus, the teaching offered to the experimental group in this study contributedeffectivelyin improving the achievement of female students in English grammar through educational activities based on the strategy of the seven-cycle learning, The researcher attributed this result to the fact that teaching according to the strategy of the seven-cycle learning has led to interaction with the educational situation through a direct task carried out by the students, which contributed to the learning of concepts functionally, related them to what was previously learned, and formed a sound knowledge structure.

This result can also be attributed to the integrated, multiple ,comprehensiveand complementary steps in the strategy of the sevencycle learning, which helped the students to organizethe information and concepts in their mindsto be then remembered and recalled, Thishas led to improved achievement, as the preparation stage contributed to draw attention and interest to the subject of 
the lesson, and identifying alternative and incorrect information that the students had, It is a prelude to the exploration stage, which contributed to increasestudents' motivation towards research, investigation and activities. The explanationstageencouraged the students to give appropriate answers, solutions and explanationsthe information and concepts with their words. The stage of application of this information to other similar situations using a set of skills such as: asking questions, proposing solutions, making decisions, taking observations. Evaluation is the stage in which the process is continuous throughout the lessons, through direct observation of the female students.

\subsection{RECOMMENDATIONS}

In light of the research results, the researcher recommends the following:

1. Encouraging English language teachers to implement the seven-cycle learningstrategy in teaching English language, given what this study revealed regarding its impact on the development of achievement.

2. Inviting those in chargeof planning the content of English language books to organize their content according to Sevencycle learning strategy.

3. Conducting similar studies to know the effect of the seven-cycle learning strategy on other variables such as: deductive thinking, critical thinking, creative thinking.

4. Conducting similar studies on other classes, and within other English language subjects. 


\section{REFERENCES:}

Al-Azmia, Adel and Sharheed, Ali (2015). The effect of using the strategy of the five-cycle learning to teach a unit in biology for basic seventh grade in the development of achievement and mathematical thinking among students in the governorate of Abyan, Republic of Yemen, The Arab Journal for the Development of Excellence, 6(01): 5-82.

Al-Dabaiba, Nader (2015). The effect of using the Bybee model for teaching mathematics indeveloping mathematical concepts and creative thinking in Jordan.Unpublished doctoral thesis, University of Islamic Sciences.

Al-Otaibi, Nawal (2008). The effectiveness of using the "learning cycle" method in the achievement of the English language and the development of deductive thinking skills among second-grade intermediate students in Makkah, an unpublished master's thesis, Umm Al-Qura University.

Al-Shatnawy, Issam and Al-Obaidi, Hani (2006). The effect of teaching according to the two constructive models of Ma'til on the achievement of ninth-grade students in mathematics, The Jordanian Journal of Educational Sciences, 2(4:) 819-802.

Alshehri, Mohammed.( 2016). The Impact of Using (5e's) Instructional Model on Achievement of Mathematics and Retention of Learning among Fifth Grade Students, Journal of Research \& Method in Education, 6(2): 43- 48.

Bybee, R.; Buchwald, C.; Crissman, S. (1989). Science and technology education for the elementary years: frameworks for curriculum and instruction. Andover, MA: The National Center for Improving Science Education.

Devrim, K; Ceren, T; Jale, Ç. (2009). Effectiveness of 5E Learning Cycle Instruction on Students Achievement in Cell Concept and Scientific pistemological Beliefs, ERIC ,NO 871023.

Eid, We'am (2014). The effect of teaching a proposed unit based on the (7E's) strategy on developing and retaining mathematical communication skills in geometry for ninth grade students in Gaza, an unpublished master's thesis, Al-Azhar University, Gaza.

Majali, Youssef (2016). The effect of using the five-cycle learning model on the achievement and developing creative thinking among seventh-grade students in Arabic language in Qasr District - Karak Governorate, Dirasat Journal, University of Jordan, 34 (0:85-56).

Sabbagh, Sumaila (2013). Aspects of Mathematical Thinking for the First, Second and Third Grades in Jordan, Damascus University Journal, 22(8): 422-319.

Tarawneh, Muhammad. (2011). The effect of using the modified learning cycle on developingcritical thinking skills for tenth grade female students in Jordan, An-Najah National University Journal for Human Sciences, 22(9): 822-504. 


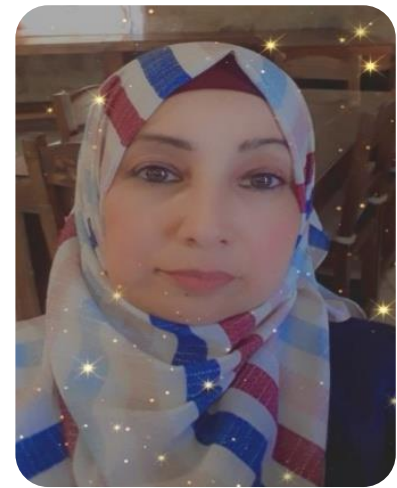

ZAHERA ABDUL-AZIZSA'IDS.BANI ATTIH

Zaherabanyatyeih7@gmail.com

THE HASHEMITE KINGDOM OF JORDAN

(THE MINISTERY OF EDUCATION) 